\title{
Transitividade e passiva
}

Maria Angélica Furtado da Cunha Universidade Federal do Rio Grande do Norte

\section{Abstract}

This paper presents a study of passive sentences of the type SUBJECT - BE - PAST PARTICIPLE - PREPOSITIONAL PHRASE. The data include formal written Portuguese as well as spoken Portuguese elicited in interviews. The pragmatic function of the passive concerning text organization is discussed. The gradient notion of transitivity is employed as an indicator of the portion of the text (foreground/background) where the passive tends to occur. 


\section{INTRODUÇĀO}

o estudarem a estrutura da narrativa e o modo pelo qual ela se identifica com determinadas formas gramaticais, 1 Hopper \& Thompson (1980) propõem o conceito de transitividade como um universal discursivo. Do ponto de vista da Gramática Tradicional, transitividade se refere à transferência de uma atividade de um agente para um paciente. $\mathrm{Na}$ visão tradicional, os três elementos da transitividade (agente, ação, objeto) co-ocorrem. Para Hopper \& Thompson não há necessidade da existência dos três elementos para que uma oração seja transitiva. A transitividade é concebida como uma noção contínua, não categórica. Dez parâmetros independentes compõem o complexo de transitividade. Cada um desses parâmetros contribui para a ordenação de orações segundo o grau de transitividade que manifestam. São eles:

1. Participantes (um ou mais)

2. Cinese (ação)

3. Perfectividade do verbo ( + ou - perfectivo)

4. Punctualidade do verbo (+ ou - punctual)

5. Intencionalidade do sujeito ( + ou - intencional)

6. Polaridade da oração (+ ou - afirmativa)

7. Modalidade da oração (+ ou - real)

8. Agentividade do sujeito ( + ou - agente)

9. Afetamento do objeto ( + ou - afetado)

10. Individuação do objeto (+ ou - individuado)

Embora independentes, os dez traços da transitividade funcionam juntos e articulados na língua, o que significa que nenhum deles sozinho é suficiente para determinar a transitividade de uma 
oração. Cada um desses traços focaliza um ângulo diferente da transferência da ação em uma porção diferente da oração.

Hopper \& Thompson associam o universal lingüístico transitividade a uma função discursiva/comunicativa: o maior ou menor grau de transitividade reflete a maneira como o falante estrutura o seu discurso para atingir seus alvos comunicativos.

Mc Cleary (1982) discorda parcialmente desta posição e sugere que a transitividade é um universal cognitivo que reflete o modo pelo qual o mundo é apreendido. Assim, os traços da transitividade "formam um complexo unificado, não porque chamem a atenção para os elementos salientes do discurso, mas porque são traços de uma situação prototípica, no mundo da referência, que o falante julga saliente." (Mc Cleary, 1982:69. Grifo meu).

Defendendo seu ponto de vista, Mc Cleary cita Slobin (1982), cuja definição de eventos transitivos prototípicos é semelhante à definição de transitividade de Hopper \& Thompson, a saber: um evento transitivo prototípico é aquele em que um agente animado intencionalmente causa uma mudança física e perceptível de estado ou locação em um paciente através de contato corporal direto. Como se pode ver, os traços típicos da oração transitiva canônica de Hopper \& Thompson se identificam com os traços que caracterizam o evento transitivo prototípico tal como definido por Slobin, à exceção do traço 'contato corporal direto'.

A universalidade do complexo de transitividade parece residir no fato de que os traços que o compõem estão relacionados ao evento causal prototípico, que tem papel importante na percepção humana da experiência. Os parâmetros da transitividade marcariam "o status de uma situação percebida como um evento causal prototípico", como sugere Mc Cleary (1982:70). Desse modo, por refletirem elementos cognitivamente salientes, assinalam elementos salientes no discurso.

Tomando como ponto de partida os parâmetros da transitividade de Hopper \& Thompson, este trabalho tem por objetivo determinar, dentre esses parâmetros, quais são relevantes na 
caracterização do Sujeito e Predicado das orações passivas. Além disso, serão propostos outros traços que caracterizem, especificamente, o Sintagma Preposicionado (Sprep) que é geralmente analisado como Agente da Passiva. Por serem uma manifestação da transitividade, as orações passivas podem ser ordenadas em uma escala de acordo com o grau de transitividade que apresentam. Assim, poderão ser classificadas como mais ou menos passivas, dependendo do grau de incidência dos traços definidores. A oração passiva canônica terá todos os traços da transitividade presentes, ocupando, portanto, a posição mais alta na escala.

A interpretação semântica das orações passivas está estreitamente ligada ao significado do complexo de transitividade de Hopper \& Thompson e ao que Slobin chama de evento transitivo prototípico: a oração passiva canônica reflete a transferência intencional de uma ação de um agente para um paciente que é totalmente afetado.

Os dados que analiso foram extraídos de diferentes corpora. Os dados do português escrito provêm de artigos publicados nas seções de Opinião e Editorial do Jornal do Brasil (JB), e de capítulos dos seguintes livros: História do Brasil, de Souto Maior (SM); Capítulos da história colonial, de C. de Abreu (CA) e Repressão sexual, de M. Chauí (MC). A escolha desses textos justifica-se pelo meu interesse no modo de narração dos eventos. As passivas do português falado foram retiradas das entrevistas do projeto Norma Urbana Culta (NURC-RJ) e do projeto Censo da Variação Lingüística (CVL), da UFRJ. Esse corpus é constituído de 134 orações passivas, sendo 97 do português escrito formal e 37 do português falado em situação de entrevista. Para efeito do cômputo dos parâmetros da transitividade só me interessam aquelas orações passivas analisáveis em Sujeito - Ser - Particípio Passado - Sprep. A cada traço presente nas passivas será atribuído valor um, e para cada oração serão somados os valores correspondentes aos traços investigados, obtendo-se, desse modo, o grau total de transitividade da oração. 


\section{TRANSITIVIDADE E PASSIVA}

Nem todos os dez parâmetros introduzidos por Hopper \& Thompson têm igual importância na determinação do grau de transitividade das passivas. Baseando-me na definição do conceito de transitividade e na interpretação semântica das orações passivas, mantive alguns dos traços originais e adotei outros. ${ }^{1}$ Dividi esses traços em três grupos: 1) traços que caracterizam o SPrep; 2) traços que caracterizam o Sujeito da passiva e 3) traços que caracterizam a Oração. Depois de analisados, esses traços são reagrupados e obtemos, então, o total de transitividade da oração passiva.

Para descrever o SPrep passivo sugiro os traços: 'intencional', 'não-controlado', 'concreto' e 'individuado'. Os traços referentes ao Sujeito são: 'referencial' e 'afetado'. Os traços que dizem respeito à Oração são: 'modalidade', 'polaridade' e 'perfectividade'.'

\section{TRAÇOS DO SPREP}

Muitas orações são acompanhadas por SPreps que não representam o que se entende semanticamente por agente. Em grande parte delas o SPrep representa o instrumento através do qual a ação verbal se realizou. Segundo alguns autores (cf. Nilsen (1973) e Givón (1984), casos como o de agente e instrumento, por exemplo, podem ser melhor caracterizados em termos de feixes de traços semânticos, ao invés de um traço discreto. Decidi adotar esse procedimento na determinação dos traços que considero relevantes para a diferenciação dos casos que os SPreps passivos podem desempenhar. Assim, substituí o componente 'agentividade' de Hopper \& Thompson pelos componentes 'intencional', 'nãocontrolado', 'concreto' e 'individuado'.

O SPrep passivo contribui com quatro dos nove traços definidores da oração passiva típica. Sua importância na atribuição do grau de transitividade se explica pelo fato de que a transferência 
da ação para o paciente se dará de forma completa, do ponto de vista do Sprep, se esse causativo for 'intencional', 'concreto' e 'individuado'. Por outro lado, orações passivas que tenham a mesma marcação para os traços de Sujeito e Oração podem diferir no que diz respeito aos traços do SPrep e, conseqüentemente, ocuparem posições diferentes na escala de transitividade, como por exemplo:

(1) Após o regresso de D. João VI para Portugal (1820) a agitação republicana foi habilmente controlada por José Bonifácio, partidário da independência com manutenção do regime monárquico. (SM, p.299)

(2) Conscientes de sua força, não esconderam alguns militares sua desconfiança e antipatia ao governo, surgindo assim as chamadas "questões militares". A primeira (1884) foi provocada por um projeto do marquês de Paraná sobre a reforma do montepio militar. (SM, p.300)

Apesar de (1) e (2) terem sido marcadas positivamente com relação aos traços do sujeito [+referencial, +afetado] e da oração [+modalidade, +polaridade, +perfectividade], à primeira foi atribuído grau 9 de transitividade, ao passo que a segunda recebeu grau 6 , devido às diferenças existentes nos traços que analisam o SPrep. Em (1), o SPrep por José Bonifácio é [+intencional, +não-controlado, +individuado, +concretol, somando, pois, 4 pontos. Em (2), o SPrep por um projeto do marquês de Paraná é [-intencional, -nãocontrolado, -individuado, +concretol, perfazendo apenas 1 ponto.

\subsection{Intencional}

Esse traço é particularmente importante na distinção entre agente da passiva, que é sempre [+intencional], e instrumento e força natural, que são sempre [-intencional]. $O$ traço 'intencionalidade' está associado ao fato de o agente estar consciente da ação que pratica. 
Embora possa agir contra sua vontade própria, obedecendo a uma ordem, por exemplo, o agente é o iniciador responsável pelo evento. $O$ agente é sempre intencional no sentido de que ele tem controle sobre suas próprias ações e sobre o efeito dessas no paciente.

Como exemplo de Sprep agente, instrumento e força natural, cito (3), (4) e (5), respectivamente:

(3) Basta ler a comovida vênia que ao defunto [general Golbery] foi dedicada pelo jornalista Paulo Francis, na Folha de São Paulo. (JB, 07/10/87)

(4) Paralelamente ao Ato Institucional $n^{\circ} 5$, pelo Ato Complementar $n^{\circ} 38$ foi também decretádo o recesso do Congresso. (SM, p.352)

(5) Em 1986, dois funcionários da mesma Angra I foram contaminados por radioatividade quando realizavam testes em instrumentos de monitoração. (JB, 08/10/87)

\subsection{Nāo-controlado}

O traço 'não-controlado' é útil na distinção entre os casos força natural e instrumento, que recebem, ambos, a marcação [-intencional]. $O$ caso instrumento só é possível se houver um agente que o manipule. Portanto, será sempre marcado como [-não-controlado] em relação ao agente que o manipula. Os três exemplos do caso força natural que ocorreram em meus dados foram marcados, analogamente ao agente, [+não-controlado] mas com ele não se confundem, pois são sempre [-intencional]. Assim, embora os SPreps agente, instrumento e força natural sejam controladores em relação à ação verbal, na medida em que afetam o paciente, apenas o instrumento é controlado.

Os exemplos (6), (7) e (8) apresentam SPreps agente, força natural e instrumento, respectivamente. Os dois primeiros foram 
classificados como [+não-controlado], enquanto o último recebeu a marcação [-não-controlado].

(6) Normalmente a casa não é nem aproveitada pelos tios. (NURC, $\mathrm{n}^{\circ}$ 25)

(7) Lamentavelmente, nos últimos meses do governo Venceslau Brás, o país foi atingido pela terrivel epidemia conhecida pelo nome de "gripe espanhola". (SM, p.330)

(8) Pouco tempo vigorou a Constituição de 1934. Em 1935 seus efeitos seriam anulados pelo "estado de sítio" então decretado. (SM, p.338)

\subsection{Concreto}

O traço 'concreto' é importante na medida em que está diretamente associado à percepção do evento transitivo prototípico. Se o SPrep passivo for concreto, mais saliente, do ponto de vista perceptivo/cognitivo, será a mudança causada no paciente. Isso implica dizer que, na sua origem, o evento transitivo prototípico é apreensível pela visão. Givón (1984:171) observa que a noção de 'saliência' pode ser mais semântica (quando o afetamento visível do objeto é destacado) ou mais pragmática (quando se destaca o fato de o objeto ser um tópico importante na comunicação). Parece-me que na passiva o aspecto semântico e o pragmático da noção de saliência se acham unidos. Além de cognitiva/perceptualmente saliente, o paciente passivo é também discursivamente importante. Como exemplo de [+concretol temos (9) e de [-concreto] (10):

(9). O cara que botou o nome. Ele botou Ala dos Coringa porque essa ala foi fundada por três colegas meu. Eles são do Acari. (CVL, $\mathrm{n}^{\circ}$ 25) 
(10) A atuação de Rio Branco na Pasta da Relação Exterior fol marcada, principalmente; pela solução de uma grave pendência relativa à fronteira Brasil-Bolívia. (SM, p.324)

\subsection{Individuado}

O traço 'individuado' só se aplica àqueles SPreps marcados anteriormente como [+intencional], ou seja, os verdadeiros agentes da passiva. Serve para distinguir entre grupo de pessoas, [-individuado], e agentes singulares, [+individuado]. Para os SPreps nãointencionais (i.e. instrumento e força natural), a marcação de 'individuado' será 0 .

A inclusão desse traço foi motivada por questões ligadas à saliência cognitiva. Do ponto de vista perceptivo, os indivíduos singulares sobressaem mais do que os grupos. $O$ estabelecimento de sua identidade os diferencia de outros membros do grupo, com quem compartilham suas propriedades de tipo (cf. Givón (1984:414)). O SPrep não-individuado, por sua vez, restringe a categoria dos possíveis agentes: dentre todos os humanos potencialmente agentes, o não-individuado aponta para o tipo de agente responsável pela ação verbal. Para exemplificar esse componente, tomemos (11), em que o agente é [+individuado], e (12), em que o agente é [-individuado]:

(11) O desfecho fora previsto e publicado anos antes por Pierre Moreau, natural de Charolais, na Borgonha, que passara algum tempo entre os holandedes, em Pernambuco. (CA, p.110)

(12) ... eu conheço até um caso de um rapaz, um caso individual que talvez não ... não interfira muito, de um rapaz de classe média querendo ser realmente policial, ele tinha vontade de ser, ele deve ter algum ... vontade de controlar os outros, assim, talvez seja um mecanismo qualquer psicológico, e ele foi simplesmente cerceado por toda a familia, ... (NURC, $\mathrm{n}^{\circ} 31$ ) 


\section{TRAÇOS DO SUJEITO}

Dentre os componentes da transitividade tal como elaborados por Hopper \& Thompson interessam-me, com relação ao sujeito formal das passivas, os que dizem respeito à referencialidade do paciente (traço 'referencial') e ao efeito da ação nesse argumento (traço 'afetado').

\subsection{Referencial}

A escolha desse traço foi motivada pelo fato de que a transferência de atividade para o paciente depende de seu caráter mais ou menos referencial. A mudança, causada pelo SPrep, no estado ou na locação do paciente será mais efetiva se esse paciente for referencial. Marcarei como [+referencial] aquele SN que implica a existência de um referente único, em oposição ao SN [-referencial], que se aplica a membros de um grupo. O traço 'referencial', portanto, assinala a distinção entre sujeitos específicos e sujeitos genéricos. A esse respeito, vejamos a passiva abaixo:

(13) Não é só: além de tornar-se figura meramente decorativa, o presidente da República só será escollhido pelo povo no primeiro turno. Se obtiver maioria absoluta, está eleito. Se não obtiver, cabe ao Congresso escolhê-lo no turno decisivo. (JB, 05/10/87)

O sujeito dessa passiva se refere a um presidente em potencial, mas ainda não determinado. Todavia, tratei esse sujeito como referencial visto que ele aponta para um referente único.

\subsection{Afetado}

A importância do traço 'afetado' reside no fato de que o grau de transferência da atividade do agente para o paciente resulta de quão afetado seja o paciente. O paciente prototípico é aquele que é totalmente afetado pela ação verbal. 
A marcação do traço 'afetado' será feita com base em critério semântico-discursivo. Isso quer dizer que, além da interpretação semântica do particípio passivo, levarei em conta informação discursiva na avaliação do afetamento do paciente.

Os traços 'afetado' e 'referencial' estão estreitamente relacionados, já que um $\mathrm{SN}$ referencial é mais completamente afetado do que um SN não-referencial. A título de exemplificação, observemse as passivas em (14) e (15), cujos pacientes foram marcados como [+referencial, +afetado] e [-referencial, -afetadol, respectivamente:

(14) O Tibet foi submergido pela China Popular em 1950. (JB, 07/10/87)

(15) Senadores e deputados também seriam eleitos pelo povo. (SM, p.310)

\section{TRAÇOS DA ORAÇÃO}

Estou interessada, nesta seção, nos componentes de Hopper \& Thompson relacionados ao modo, ao aspecto e à polaridade da oração. Da perspectiva da oração passiva, a transferência da atividade se dá se a ação verbal é apresentada como real ou concreta ('modalidade'), se essa ação foi concluída ('perfectividade') e se a oração é afirmativa ('polaridade').

Note-se que a marcação dos traços 'modalidade' e 'perfectividade' baseia-se no modo e no aspecto do verbo ser e a marcação do parâmetro 'polaridade' abrange a seqüência SER - PARTICÍPIO.

\subsection{Perfectividade}

A marcação do traço 'perfectividade' repousa em critério pragmático, ou seja, o modo como a ação é apresentada. $O$ aspecto do verbo traduz o ponto de vista a partir do qual o falante/escritor considera a ação expressa pelo verbo. Essa ação pode ser considerada 
como concluída, isto é, observada no seu término ou não-concluída, isto é, vista na sua duração. No primeiro caso, a passiva é marcada como perfectiva, enquanto no segundo é não-perfectiva.

Em termos da cognição, os eventos são mais salientes quando completos. Assim, o evento transitivo prototípico é perfectivo (cf. Givón (1984:281) e Hopper \& Thompson (1980)). O grau de transferência da ação depende da conclusão da ação verbal: nas orações completas a transferência pode se dar de forma total, ao passo que nas orações inconclusas a transferência pode não se dar, ou acontecer apenas parcialmente. A propósito da relação entre transitividade e perfectividade, Givón (1984:157) nota que essa relação repousa na inferência pragmática de afetamento do paciente. Em suas palavras, "quanto mais completo for um evento, tanto mais será provável que o paciente registre os efeitos da ação."

Uma vez que o particípio passado é de aspecto concluso ou perfeito, a marcação do traço 'perfectividade' nas passivas levará em conta o aspecto do auxiliar ser. (16) e (17) são exemplos de ações perfectiva e imperfectiva, respectivamente:

(16) Bom, eu tinha, tinha um carro. É, exato, eu tenho um carro, mas eu tinha um carro que me foi dado pelo meu pai ainda quando eu estudava na faculdade. (NURC, $\mathrm{n}^{\circ} 21$ ).

(17) Chefe da milícia e em geral da administração era o governador-geral com assento na Bahia. A milicia era representada pela tropa paga. E pelas ordenanças, espécie de guarda nacional. (CA, p.94)

\subsection{Modalidade}

Quanto ao modo, as ações são divididas em [+real], quando correspondem a um evento cuja ocorrência é assegurada no texto, e [-real], quando simplesmente não aconteceram ou são apresentadas como tendo ocorrido num mundo hipotético, incerto. Desse modo, 
o parâmetro 'modalidade', assim como 'perfectividade', relacionase à perspectiva sob a qual o narrador apresenta o evento. Indica a atitude (de certeza, dúvida, suposição, etc.) da pessoa que fala/ escreve em relação ao fato que enuncia.

É no nível da oração que esse parâmetro é considerado. Estando relacionada ao modo de embalagem, a marcação do traço 'modalidade' se baseia não só no tempo/modo do ser passivo mas também na natureza da oração passiva. Assim é que as passivas que expressam um evento hipotético ou possível (como as orações condicionais ou as orações com auxiliares modais, por exemplo), ainda que contenham o auxiliar no indicativo, serão marcadas como [-real]. (18) é um exemplo de passiva [+real] e (19) de [-reall:

(18) Ele, olha, ele é freguês do Instituto Pasteur. Ele foi mordido por cachorro, várias vezes, foi mordido pelo cavalo do leiteiro e foi mordido por uma porca. (CVL, $\mathrm{n}^{\circ} 33$ )

(19) Bom, o bucho também deve ser preparado por uma pessoa de muito escrúpulo ... (NURC, no 27)

\subsection{Polaridade}

Esse parâmetro divide as passivas em [+afirmativa] (ex. (20)) e [-afirmatival (ex. (21)):

(20) A ruptura da Aliança Democrática - pedaços de esperança para todos os lados - é o Brasiliacentro. Foi tramado pelo próprio governo. (JB, 30/09/87)

(21) A própria Isabel não era poupada pela propaganda republicana que a chamava de "carola". (SM, p.302)

As orações negativas são pressuposicionalmente mais marcadas do que as afirmativas correspondentes. Nas negativas o 
sujeito e o objeto, por serem pressupostos, são geralmente definidos e, portanto, referenciais (cf. Givón (1979)). Assim, as orações negativas, relatando não-ações ou não-eventos (à exceção daquelas com verbos de acepção negativa, como (21)), estão implicadas na determinação da referencialidade e do afetamento do paciente e, conseqüentemente, do grau de transitividade da passiva.

\section{GRAU DE TRANSITIVIDADE DAS PASSIVAS}

Com base na marcação dos componentes da transitividade propostos para a passiva, elaborei a seguinte matriz de traços que evidencia a diferença entre os tipos de SPreps:

\begin{tabular}{|l|c|c|c|c|c|}
\hline SPrep/Traços & Intenc. & Não-contr. & Conc. & Indiv. & Total trans. \\
\hline Agente & + & + & $+/-$ & $4 / 3$ & \\
\hline Força Natural & - & - & - & 0 & 2 \\
\hline Instrumento & - & - & $+/-$ & 0 & $1 / 0$ \\
\hline
\end{tabular}

Quadro I: Matriz de traços do SPrep passivo

Os SPreps das 134 passivas analisadas funcionam semanticamente como agente em 77\% (103) dos casos, como instrumento em $21 \%$ (28) e como força natural em $2 \%$ (3). A distribuição dos três casos semânticos do SPrep passivo nos dados da escrita e da fala está no quadro II:

\begin{tabular}{|l|c|c|}
\hline Caso semântico & Escrita & Fala \\
\hline Agente & $69(71 \%)$ & $34(92 \%)$ \\
\hline Instrumento & $26(27 \%)$ & $2(5 \%)$ \\
\hline Força natural & $2(2 \%)$ & $1(3 \%)$ \\
\hline
\end{tabular}

Quadro II: Distribuição dos casos semânticos dos SPreps passivos 
Os resultados acima indicam que o recurso de não-identificação do agente, através da apresentação do instrumento como causador do evento, é mais operante na escrita do que na fala. Os dois SPreps instrumentos registrados na fala ocorreram nos dados do NURC, assim como o único caso força natural. Isso nos leva a pensar que a estratégia de omissão do agente e identificação do instrumento nas passivas pode estar relacionada ao grau de formalidade e elaboração do registro ou ao próprio assunto da comunicação. A escrita, mais formal e elaborada do que a fala, apresenta uma freqüência expressiva de SPreps instrumentos. Quanto à fala, é nos dados do NURC, provindos de falantes mais influenciados pelo padrão da escrita, que a ocorrência do caso instrumento se dá.

No geral, as passivas com SPrep agente oscilam entre o grau 9 de transitividade e o grau 6. Cerca de $1 / 3$ das orações se concentra no grau 8 da escala, tanto na escrita quanto nos dados da fala do CVL. Nos dados do NURC, a maior concentração está no grau 4. As passivas com agente do NURC são de baixa transitividade por ocorrerem em trechos pouco narrativos. Trata-se de passagens que esclarecem dúvidas do entrevistador, apresentando situações hipotéticas, com pacientes genéricos. Na passiva seguinte, os traços 'referencial' e 'afetado' (do sujeito), 'modalidade' e 'perfectividade' receberam marcação negativa:

(22) - Mas também você falou: as pessoas escolhem esses candidatos. Qualquer pessoa pode se candidatar ou, ou há necessidade dele pertencer a um partido ou ...

- Ele tem que ser apresentado por um partido, mas ele pode não pertencer ao partido e se integrar ao partido, no momento em que vai ser lançada a candidatura dele. (NURC, $n^{\circ} 112$ )

Em contraposição, as passivas da escrita e do CVL com grau 8 de transitividade são tipicamente narrativas, como em (23) e (24): 
(23) O desenlace ocorre quando um pastor, certo de que trará boas notícias ao rei, vem a Tebas e conta a Édipo que, de fato, ele não é filho de Polibo e Mérope, podendo regressar a Corinto sem medo, pois para lá fora levado pelo pastor que o encontrara no fundo de um despenhadeiro, com uma pedra amarrada aos pés, abandonado e à morte. (MC, p.57)

(24) Ele, olha, ele é freguês do Instituto Pasteur. Ele fol mordido por cachorro, várias vezes; fol mordido pelo cavalo do leiteiro e foi mordido por uma porca. Que tinha uma ninhada de leitão lá na chácara, ele foi mexer com a porca, não é? Atazanar a porca, não é? E a porca, ó, passou-lhe o dente. (CVL, no 33)

Nos fragmentos transcritos acima, narram-se eventos apresentados como concluídos, de que participaram, como pacientes, referentes específicos.

No que diz respeito às passivas com SPrep instrumental, elas se distribuem entre os pontos 6 e 1 na escala de transitividade. $O$ grau típico dessas orações parece ser o 5 , onde se concentra o maior número de passivas com SPrep instrumental (cerca de 46\%). Os outros pontos da escala apresentam poucas ocorrências (duas, em média).

A passiva abaixo recebeu grau 5 de transitividade. Seu paciente é referencial e afetado e a ação é real:

(25) O jeito é fechar os olhos e ousar. Não está fácil. E o mais preocupante é que Sarney vai sendo envolvido e enrolado pelos fios de muitos novelos e passa os sinais de hesitação. Daí para o recuo é um passo. (JB, 30/09/87)

As três passivas com SPrep força natural estão nos pontos $7 \mathrm{e}$ 6 da escala de transitividade. Devido à marcação positiva do traço 'não-controlado', essas passivas podem ser mais altamente transitivas do que aquelas com SPrep instrumental (cf. quadro I). 
É no ponto 6 da escala de transitividade que as passivas com SPrep agente, instrumento e força natural podem convergir. Esse ponto representa o grau mínimo de transitividade para as passivas com SPrep agente ou força natural e o grau máximo para as passivas com SPrep instrumento.

Para os traços do sujeito-paciente encontrei os seguintes resultados:

\begin{tabular}{|l|c|c|}
\hline Traço & Escrita & Fala \\
\hline Referencial & $89 / 97(92 \%)$ & $29 / 37(78 \%)$ \\
\hline Afetado & $67 / 97(69 \%)$ & $24 / 37(65 \%)$ \\
\hline
\end{tabular}

Quadro III: Marcação dos traços do sujeito

O sujeito-paciente das passivas analisadas é predominantemente referencial, tanto na escrita quanto na fala. Embora não seja exclusivo da passiva, o paciente referencial é característico da narrativa. Em narrativas, é comum que falemos sobre objetos ou pessoas específicas que são entidades do mundo real. Ou seja, os argumentos referenciais são mais provavelmente tópicos discursivos do que os não-referenciais ou genéricos, pois, em geral, é sobre indivíduos singulares que se constrói o discurso.

$\mathrm{O}$ afetamento do paciente deu-se em quase $70 \%$ das passivas da escrita e da fala. Isso quer dizer que, na grande maioria das orações, a transferência da atividade do agente para o paciente foi efetuada, acarretando mudança no estado ou na locação do sujeitopaciente.

Passemos, agora, à análise dos traços que dizem respeito ao predicado passivo. Os resultados obtidos encontram-se no quadro IV:

\begin{tabular}{|l|c|c|}
\hline \multicolumn{1}{|c|}{ Traço } & Escrita & Fala \\
\hline Perfectividade & $50 / 97(52 \%)$ & $15 / 37(41 \%)$ \\
\hline Modalidade & $61 / 97(63 \%)$ & $18 / 37(51 \%)$ \\
\hline Polaridade & $92 / 97(95 \%)$ & $35 / 37(95 \%)$ \\
\hline
\end{tabular}

Quadro IV: Marcação dos traços da oração 
Quanto ao traço 'perfectividade', que representa ação concluída, $52 \%$ das passivas da escrita e $41 \%$ das passivas da fala foram classificadas como perfectivas. Na fala, é nos dados do NURC que a incidência de passivas imperfectivas é mais acentuada. Apesar da paucidade dos dados em geral, enquanto $66 \%$ das passivas do CVL são perfectivas, $15 \%$ das passivas do NURC são perfectivas. Mais uma vez creio que a diferença nos resultados dos dados do CVL e do NURC relaciona-se ao tipo de discurso e ao assunto de cada um dos corpora. Como disse anteriormente, as entrevistas do NURC não representam narrativas típicas. Em geral, ofalante discorre sobre temas específicos (alimentação, comércio exterior e política nacional, vestuário, por exemplo), propostos pelo entrevistador. Nesse sentido, não é surpreendente que as passivas coletadas sejam predominantemente imperfectivas, com o auxiliar passivo no indicativo presente ou futuro.

Uma vez que a perfectividade do verbo está intimamente relacionada à interpretação semântica que atribuímos à passiva, esperava que a freqüência de passivas perfectivas fosse maior do que a verificada. Disse que o grau de transferência (total ou parcial) da atividade resulta do grau de conclusão da ação verbal: quanto mais conclusa a ação, maior a transferência da atividade. No entanto, se compararmos o quadro III com o quadro IV, veremos que a percentagem de sujeitos afetados é maior do que a de verbos perfectivos, tanto na escrita quanto na fala. Ou seja, a transferência da atividade - e consequiente afetamento do paciente - pode-se dar sem que a ação esteja necessariamente concluída. Cabe ressaltar, em primeiro lugar, que Hopper $\&$ Thompson opõem objeto totalmente afetado, de um lado, a objeto parcialmente afetado ou não-afetado, de outro. Em minha análise, porém, a oposição se dá entre pacientes total ou parcialmente afetados e pacientes não-afetados. Essa diferença na marcação do traço 'afetado' pode ser, em parte, responsável pelo fato de que registrei pacientes afetados em passivas imperfectivas e pacientes não-afetados em passivas perfectivas. Em segundo lugar, vale lembrar que a marcação do traço 'perfectividade' se baseia em critério pragmático, isto é, o modo como a ação é embalada, ao passo que a marcação de 'afetado' se apóia em critério 
semântico-textual - a informação contida no discurso juntamente com a interpretação semântica do particípio determinam o afetamento do sujeito-paciente da passiva. Creio que a combinação dos traços [+perfectividade, -afetado] e [-perfectividade, +afetado] é possível devido à utilização de critérios diferentes na marcação dos referidos traços. Concluo que, apesar da forte correlação probabilística entre a perfectividade do verbo e o afetamento do sujeito passivo, há outros fatores, além da imperfectividade verbal, que favorecem o não-afetamento do sujeito, como a modalidade 'irrealis' da passiva, a polaridade negativa da oração e a nãoreferencialidade do sujeito.

O traço 'modalidade' recebeu marcação positiva em $63 \%$ das passivas da escrita e $51 \%$ das passivas da fala. Se separássemos as passivas do CVL das do NURC, obteríamos para as primeiras um percentual mais alto de passivas realis (65\%) do que para as segundas (31\%). Na escrita, é nos textos de História do Brasil que se concentra a maior frequiência de passivas 'realis' (70\% em SM e 83\% em CA). O caráter narrativo do texto histórico justifica a ocorrência do modo realis na grande maioria das orações. Trata-se, em princípio, do relato de seqüências de ações que realmente ocorreram, que têm correspondente no mundo real e que são embaladas como tal.

Quanto à polaridade, as orações passivas são majoritariamente afirmativas (95\%, tanto na escrita quanto na fala). Esse resultado era esperado visto que, de um modo geral, o discurso se funda sobre o relato de eventos positivos. Desse modo, a narração de eventos negados é circunstancial, ocorrendo nos contextos em que a afirmativa correspondente à negativa foi mencionada anteriormente ou nos contextos em que a possibilidade da afirmativa correspondente é conhecida pelo ouvinte/leitor.

Do que foi exposto, concluo que a aplicação do conceito de transitividade às passivas com SPrep parece explicar o fato de que essas construções não são categóricas: quanto mais se afasta da interpretação semântica canônica, mais a passiva desce na escala de transitividade. 
Os traços sugeridos para a caracterização do SPrep passivo permitiram destacar que, sob o rótulo tradicional de "agente" que esse argumento recebe, incluem-se o caso instrumento e, ainda, o caso força natural.

\section{PASSIVA, FIGURA E FUNDO}

Em Hopper \& Thompson, a transitividade oracional está relacionada a uma função pragmática/comunicativa. $O$ modo como o falante/escritor organiza o seu texto é determinado, em parte, pelos seus objetivos comunicativos e, em parte, pela sua percepção das necessidades do ouvinte/leitor. Nesse sentido, o discurso apresenta uma distinção entre o que é central e o que é periférico. Para que a comunicação se processe satisfatoriamente, ou seja, para que emissor e receptor possam partilhar a mesma perspectiva, o emissor orienta o receptor a respeito do grau de centralidade e de perifericidade dos enunciados que constituem o seu discurso. Em termos da estrutura do texto, a divisão entre central e periférico corresponde à distinção entre figura e fundo. $O$ grau de transitividade de uma oração reflete sua função discursiva característica, de modo que orações com alta transitividade assinalam porções centrais do texto, correspondentes à figura, enquanto orações com baixa transitividade marcam as porções periféricas, correspondentes ao fundo.

Por figura entende-se aquela porção do texto que apresenta a seqüência temporal de eventos que constitui a comunicação central. Em (26), a função da passiva em negrito é transmitir a comunicação central do fragmento transcrito. Todas as outras orações são material de apoio, que detalham a comunicação feita - a dominação dos. integralistas:

(26) Na madrugada de 11 de maio de 1938 [os integralistas] tentariam, com um mal organizado ataque ao Palácio da Guanabara, 
apoderar-se do governo. Foram facilmente dominados pelas forças dirigidas pelo ministro da Guerra; alguns atacantes foram sumariamente fuzilados, outros detidos e o chefe integralista exilado. (SM, p.340)

Às porções figura e fundo de um texto associa-se um feixe de propriedades, traduzidas pelos componentes da transitividade. Dito de outro modo, os componentes da transitividade mantêm uma relação de co-ocorrência por desempenharem funções discursivas comuns, que são as de assinalar as partes centrais e as periféricas de um dado texto. Desse modo, quanto mais alto uma oração se situar na escala de transitividade, tanto mais provável que ela seja interpretada como figura, e vice-versa: quanto mais baixa sua transitividade, tanto mais provável sua interpretação como fundo. Portanto, há uma correlação probabilística forte entre a marcação dos componentes da transitividade $e$ a distinção entre figura $e$ fundo.

Com o fim de verificar se as passivas corroboram essa correlação, segui dois procedimentos: em primeiro lugar, calculei a média de transitividade das passivas figura e a média de transitividade das passivas fundo nos textos sob análise; em segundo lugar, computei, um por um, os traço da transitividade que as passivas figura e as passivas fundo exibem. Com o primeiro procedimento, obtive os seguintes resultados: num total de 9 pontos, as passivas da figura perfazem, em média, 7.3 pontos, enquanto as passivas do fundo atingem 5.4 pontos. Os números obtidos confirmam que há uma correspondência entre o grau de transitividade da passiva e sua interpretação como figura ou fundo. Com relação ao segundo procedimento, isto é, computação um a um dos traços da transitividade, o quadro $\mathrm{V}$ mostra a freqüência de traços de alta transitividade nas passivas: 


\begin{tabular}{|l|c|c|}
\hline Traços & Figuras & Fundos \\
\hline Intencional & $82 \%$ & $74 \%$ \\
\hline Não-controlado & $90 \%$ & $75 \%$ \\
\hline Individualizado & $31 \%$ & $21 \%$ \\
\hline Concreto & $94 \%$ & $87 \%$ \\
\hline Afetado & $92 \%$ & $54 \%$ \\
\hline Referencial & $96 \%$ & $83 \%$ \\
\hline Modalidade & $82 \%$ & $45 \%$ \\
\hline Polaridade & $100 \%$ & $92 \%$ \\
\hline Perfectividade & $76 \%$ & $32 \%$ \\
\hline Média dos traços & $74 \%$ & $57 \%$ \\
\hline
\end{tabular}

Quadro V: Freqüência de traços de alta transitividade nas passivas

As percentagens do quadro $V$ estão de acordo com os resultados obtidos no primeiro procedimento (i.e., a avaliação da média de transitividade das passivas figura e fundo). As passivas da figura apresentam valores mais altos do que as passivas do fundo quando se computa cada traço da transitividade de persi.

As correlações numéricas entre figura/fundo e grau de transitividade confirmam a hipótese de que quanto mais alto uma oração se situar na escala de transitividade, maior a probabilidade de que ela seja interpretada como figura. Tanto na avaliação da média de transitividade das passivas figura e fundo quanto na computação um a um dos traços da transitividade a distinção entre figura e fundo se manteve, tendo as passivas da figura obtido escores mais altos do que as do fundo.

Em meus dados, a distribuição das passivas nas porções figura e fundo dos textos analisados pode ser vista no quadro VI:

\begin{tabular}{|l|c|}
\hline Figura & $50(37 \%)$ \\
\hline Fundo & $84(63 \%)$ \\
\hline Total & $134(100 \%)$ \\
\hline
\end{tabular}

Quadro VII: Distribuição das passivas nas porçôes figura e fundo 
Os números do quadro VII indicam que a função pragmática da passiva, no que diz respeito à estruturação do texto, é a de contextualizar ou servir de apoio ao fio narrativo. De um modo geral, a passiva não é usada para desenvolver ou avançar a linha central dos acontecimentos, mas sim para prover material que o falante/ escritor julga relevante para o entendimento do que comunica. A predominância da passiva na porção fundo reflete o fato de que o produtor do texto não apresenta a passiva como parte da linha central da sua comunicação.

\section{NOTAS}

' Os traços que compõem meu complexo de transitividade se originam de fontes diferentes: alguns foram propostos por Hopper \& Thompson (1980), como os do sujeito e da oração; os do Sprep foram aproveitados da Gramática de Casos.

2 Embora estejam centrados no predicado, os traços 'modalidade', 'polaridade' e 'perfectividade' podem se referir a toda a oração, em contextos especiais (Cf. seção 5).

\section{REFERÊNCIAS BIBLIOGRÁFICAS}

GIVON, Talmy. On understanding grammar. New York, Academic Press, 1979. . Symtax. A functional-typological introduction. v. I. Amsterdam, John Benjamins, 1984.

HOPPER, Paul J. \& THOMPSON, Sandra A. Transitivity in grammar and discourse. Language 56(2): 251-299, 1980.

MC CLEARY, L. E. Transitivity and grounding in a Portuguese narrative text. M. of Arts Thesis. University of California, 1982. mimeo.

NILSEN, D. L. F. The instrumental case in English. The Hague, Mouton, 1973.

SLOBIN, D. I. The origins of grammatical encoding of events. In: HOPPER, P. \& THOMPSON, S. A. (eds.) Syntax and semantics. v. 15. Studies in transitivity. New York, Academic Press, 1982. 
Fonte dos dados

CAPISTRANO DE ABREU, J. Capítulos de bistória colonial:1500-1800 \& Os caminhos antigos e o povoamento do Brasil. Brasília, Editora Universidade de Brasília, 1982.

Censo da Variação Lingüística (CVL) no Rio de Janeiro. Rio de Janeiro, UFRJ, Faculdade de Letras, 1982.

CHAUÍ, M. Repressão sexual. São Paulo, Editora Brasiliense, 1984.

Estudo da norma lingüística urbana culta no Rio de Janeiro (Projeto NURC). Rio de Janeiro, UFRJ, 32/04/02 p. 003.

Jornal do Brasil. Rio de Janeiro, 1987.

SOUTO MAIOR, A. História do Brasil. São Paulo, Companhia Editora Nacional, 1977. 